\title{
The Impact of New Media Technology on Education in the Mobile Internet Era
}

\author{
Fang Hongfeng \\ Collage of Arts\&Media, Tongji University, No. 4800 Cao'an Highway, Shanghai \\ Email: 61579894@qq.com
}

\begin{abstract}
From the application of new media in learning, this paper divides new media learning into two categories: application in traditional classroom and network learning, and expounds the changes brought about by the development of science and technology to the two types of learning modes and the current situation of new media learning. It predicts the possibility of new media network education extending from online learning to online self-study, then to academic education, as well as the possibility of adaptive learning, and the change of learning style theory under the influence of new media and network development.
\end{abstract}

Keywords: New media, traditional education, autonomous learning, network education, adaptive learning

In the era of mobile Internet, as an important part of educational technology, new media technology has been widely used in modern education and teaching practice, forming a new mode of education or learning. Through questionnaires, the learners' use of new media equipment and resources was investigated. The sample size of the survey is $72,81 \%$ of which are college students. Most of the data in this paper come from this survey report. The author finds that today's college students spend about 4 class hours a day in classroom teaching, while most of them spend almost the same time in learning on new media equipment as in classroom teaching. Nearly $20 \%$ of students spend more than 7 hours a day on study using new media (Fig. 1). Thus, new media equipment has become the main way or tool for college students to learn. According to the different forms of application of new media devices or platforms, this paper divides the application objects of new media teaching into classroom teaching and network education.

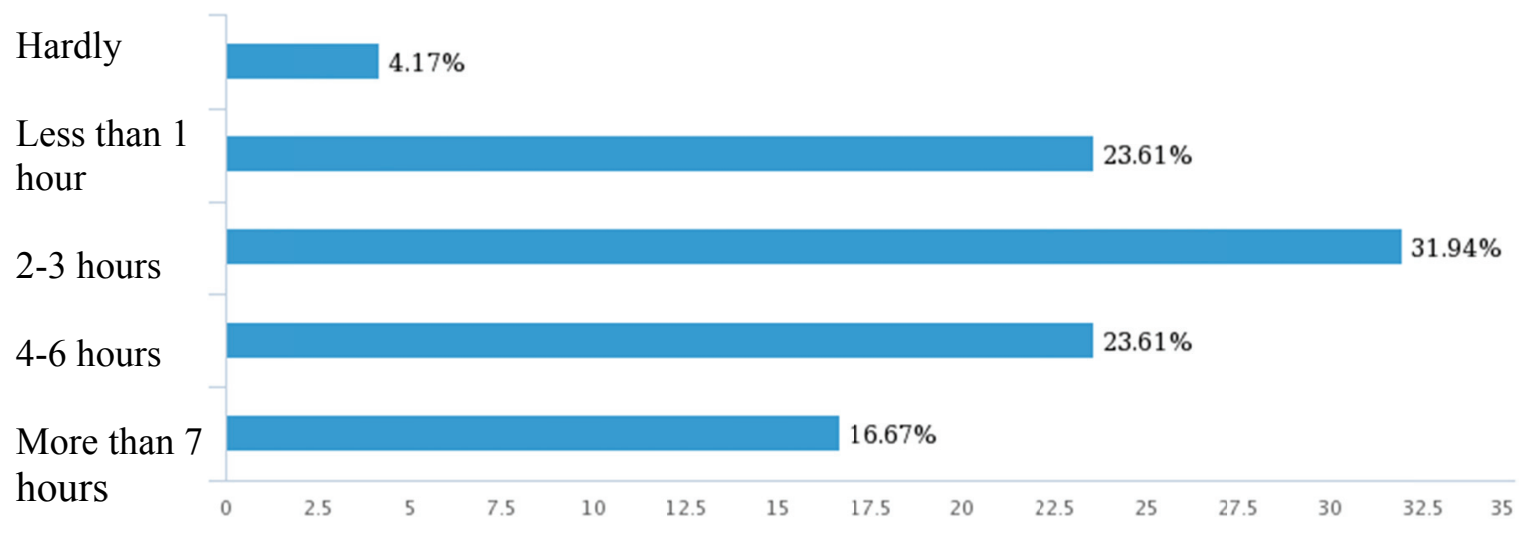

Figure 1. Time spent by learners using new media devices every day

\section{New Media Technology in Classroom Education}

Nowadays, classroom teaching increasingly combines traditional teaching methods with modern teaching methods, constantly improving the teaching support service system and improving the quality of teaching service. With the application of modern educational technology, great changes have taken place 
in educational mode and teaching methods. New technologies and new media devices for teaching emerge in endlessly.

In classroom teaching, the use of new media teaching methods must be subordinate to all kinds of teaching objectives. Only by properly handling the relationship between methods and contents can the effect of classroom teaching be improved. In what ways can the new media help the traditional teaching mode? As the operator of media equipment and the publisher of media information, what content will teachers choose to express in the form of new media? Which majors or courses are more suitable for new media? The author sums up the similarities of the existing disciplines and conducts a survey of the classroom new media content contacts among those who, for example, study or engage in certain professions. Survey data show that the proportion of students in different majors who are exposed to new media devices in class is close, among them, the proportion of video clips is larger. More than half of learners have seen videos of lectures, operations, computer software and the PPT lectures in class. About $20 \%$ of the learners said they had been exposed to new media devices such as video game player or somatosensory manipulation in class. So how are these new media contents presented?

Classroom teaching requires teachers to face a group. Most schools have multimedia classrooms. In multimedia classrooms, teachers' terminals are equipped with desktop computers, audio and video players, and interfaces with laptops and storage devices. Students can watch the new media content played by teachers from the projection screen or TV set, and some special video and audio classrooms will be equipped with special playback and viewing equipment.

At present, the popular electronic courseware (PPT, PDF, Focusky, etc.) is a kind of media form that most teachers are willing to use. Electronic courseware is also applicable to concepts, principles, case analysis, questions and answers. Electronic courseware can be accepted by teachers, and has its obvious advantages: firstly, electronic courseware omits the teachers' labor and time to use blackboard writing, and also resolves the embarrassment of some teachers who do not write beautifully; secondly, electronic courseware can be reused for a long time as it is updated slightly; thirdly, electronic courseware is not only used in blackboard writing, but also in electronic courseware. It can input text, graphics, and insert pictures, animations, videos, music or external links in a variety of forms. Finally, the electronic courseware can be presented in a suitable layout, with pagination, animation and other forms of presentation, and can also be flipped forward or jumped forward, which is more conducive to the control of the rhythm of the lecturer. However, in recent years, electronic courseware is also facing some difficulties. Because of its various advantages, it plays an important role in the classroom and becomes the main body of teaching, thus losing the flexibility of the original teaching and weakening the attraction of the classroom. Furthermore, some students begin to focus on copying courseware, which reduces the focus and interaction of lectures. Even many students choose to leave the classroom after acquiring electronic courseware resources.

As a new media material, film and TV series are more and more presented in various classes. For example, stories in movies and TV plays are mostly based on historical or realistic themes, and there are many situations of human social life. For example, teachers can use legal and political stories in movies and TV plays as cases to teach law students. Most of the pictures in the movies and TV plays are exquisite, which is a kind of enjoyment for students and is welcomed by more students. These materials are mostly intercepted or recorded by software and inserted into teachers' electronic courseware.

In some operation-based classes, besides direct demonstration, teachers also show students live or animated videos of experiments or operations. For example, in the classroom of computer software operation, besides instructing students to solve problems step by step through on-the-spot operation, teachers will also share the video of software operation demonstration to students in the form of a web link or a copy of data on a USB disk for their review after class.

At present, some new classroom will introduce multi-dimensional seats loaded with virtual games, VR glasses, simulation cabins interacting with operators and other somatosensory systems or equipment to assist teaching. Some content of situational teaching, which requires direct participation, allows students to practice in similar artificial intelligence virtual scenes, can improve learners' sense of scene and learning effectiveness, such as navigation, surgery, tower crane and other technical training courses. These simulations need to be performed in specialized laboratories.

In recent years, AR glasses and their broadcasting equipment, VR shooting and display, the rise of artificial intelligence robots have brought new sensory dimensions to people. Many scholars or investors 
are optimistic about this new form of media display. Many teachers are studying how to apply these technologies to the field of education and improve students' new sensory training.

\section{New Media Technology in Network Education}

With the rapid development of network technology, the outbreak of information and the enhancement of big data analysis ability, it promotes the production, dissemination and development of new media content. Nowadays, the new media has a better development environment than other traditional ones. The use of new media equipment has been quite popular, and the technology is becoming more and more perfect. Different from traditional education, new media education platform which relies on network emerges at the historic moment. New media network education has many advantages such as interaction, instantaneity, sharing, comprehensiveness, multi-function, socialization and individualization in various fields of education and teaching. New media network education has the characteristics of network, mobility, entertainment, low entry threshold and rich content.

New media teaching has been promoted from the integration of learning technology and strategy to the emphasis on interaction and data analysis, and then to the improvement of visual technology and intelligent technology. New technology is more and more advanced, and its application prospects and potential significance in the field of education are also growing. Online education platform is the mainstream way of online education. Through cooperation with institutions, individual teachers are stationed in order to provide online and on-demand teaching resources for learners. Typically, there are four types: 1) B2B2C platform type: comprehensive course learning platform, through the selection of excellent courses at home and abroad, to provide users with a complete set of closed-loop experience from "watching Videos - making course notes - answering questions - question bank exercises"; 2) B2C service type: through the search of self-manufacturing high-quality content, targeted service specific. Group; 3) counseling tool type: mainly replicate user learning through answering questions, intelligent papers, breaking through customs and doing questions, mostly app-based, such as ape question bank, asking him homework, hundred words chopping; 4) network school type: mainly provide real one-to-one or more online teaching, teachers and students through video counseling communication, belong to the network tutor platform.

Network learning mobility relies on advanced Internet and multimedia technology. Students and teachers use mobile devices for interactive teaching. The development of mobile learning has gone through three stages. In the first stage, mobile devices are used to send knowledge. In the second stage, mobile devices are used to support, improve and expand learners' mental models and thinking processes. The third stage is learning in the living environment and the actual situation. After three stages of development, mobile learning has become more and more perfect, which is considered to have been or will be widely used in the field of higher education in China in the near future.

The entertainment of online learning is mainly manifested in various emerging audio-visual media platforms. Audio-visual media platform has a large number of users, such as short video, live broadcasting, reading, broadcasting and other platforms. There are many audio and video resources for teaching, which make the learning process based on entertainment. Short video resources are mostly produced by individuals or small communication agencies. One is the operation skill with strong visual sense, which is explained by narration, such as teaching writing, painting, photographing, cooking, software operation, etc. There are also some theoretical knowledge or information content, using the way of hosting, presenting the video of teachers' explanation, or adding some case videos, such as health maintenance, language, life tips. In addition, there are videos of teaching make-up, dancing, doing experiments and so on.

The main content of education and teaching on live broadcasting platform mainly focuses on lectures, classroom teaching, skill operation, etc. The form of reading and broadcasting platform is mainly to broadcast audio resources with classified channels. Some channel programs are complete reading books, some will extract the essence of the book content to introduce and explain, and some are the introduction of ideas and principles. Social networking platform is also a popular online teaching place. Mainly based on the social platform of various groups, such as QQ group, Wechat group, Wechat public channel, small programs, and live broadcasting room. These instructions are directed at a specific group, 
using live broadcasting or video broadcasting, in the form of one-to-many. They use phonetics and pictures as the main media to teach theoretical courses.

One of the main characteristics of online learning is that its access threshold is relatively low. This also compensates for the needs of some learners who can't attend the diploma education, workers who want to increase their vocational skills, or students who want to improve besides the diploma education.

Network new media education meets the needs of many learners, but it is still a new thing, there is no complete teaching framework or norms. In the production of educational content, every network user can become the author, which makes the network educational resources confused and unreliable, so it also needs to pay a certain amount of time to select. From the survey, we found that learners' choice of online teaching platform and content type is more inclined to professional online learning platform, the content of which is mostly narrative video or interactive type similar to video phone. Secondly, audiovisual interactive network live broadcasting platform is also popular. In addition, about 30\% to $40 \%$ of learners will choose such online learning channels, which are video-audio demonstration platform, interactive Wechat and QQ group, used to evaluate the test question bank and various online blog articles and libraries.

\section{Autonomous Learning Using New Media Equipment}

With the enrichment and humanization of new media carriers and their channels of dissemination and display, students have shifted the main place of acquiring knowledge from classroom to other space such as residence. The main channel of learning has shifted from teachers or books to new media devices. In the 1990s, tapes, videotapes and other audio and video carriers and players became the earliest new media equipment for recording and playing audio and video content. Duplicators and CD players were also popular for a while. Nowadays, due to the limitations of capacity, reproducibility, compatibility and playback convenience, these carriers have gradually faded out of the historical stage after the emergence of storage media such as personal computers, compact disks and hard disks which are easier to record and erase. Nowadays, smartphones, tablets and laptops have become the main devices. They have quickly occupied the global market since 2000. These devices are not only portable, easy to record and copy, but also have larger storage capacity. They can run a lot of software, use the network and interact with multiple people in real time. Most college students can carry devices with them and use debris time to learn. All kinds of smart wearing equipment and household appliances have the characteristics of searching information on the internet, interacting with operators, self-learning and updating, and identifying operators' habits and preferences by using big data. They are also gradually accepted by the public and applied to the field of learning.

Nowadays, many teaching contents are based on new media forms. Many teachers will arrange homework that needs to be completed by new media devices such as computers. In addition to using computer and other input devices for writing arrangement, programming calculation, drawing production, as well as the operation of various computer software, students will also use the network for search and research. In addition, due to the development of the network and the convenience of information collection, many students are also inclined to use new media platforms or devices for autonomous learning.

New media equipment and network teaching platform provide students with a variety of learning forms and rich and colorful learning content. It breaks the limitation of time and space and provides allround and multi-angle learning guidance. We randomly sampled 57 college students to investigate the types of new media devices for assisted learning, and found that computers and smartphones become necessary devices for autonomous learning (about $90 \%$ of learners often use them). Tablets are often used as alternatives to computers and mobile phones (about 30\% of learners often use them). Smart wear, electronic video player and other media playback devices are occasionally used for learning (about $10 \%-15 \%$ of learners often use them). At present, AR glasses and AI robots, which are popular in research and investment fields, are seldom used in the sample of students we surveyed.

The new channels and ways of information collection stimulate students' enthusiasm and initiative in learning. Constructivist learning concept is being applied to more college classroom education. Constructivism holds that learning is not the transfer of knowledge from teachers to students, but the process in which students construct their own knowledge. The learner is not a passive information 
absorber, on the contrary, he should actively construct the meaning of information. This kind of construction cannot be replaced by others. [1] Its main feature is to rely on the learners' life experience, actively explore and solve problems through communication and cooperation. In the era of knowledge explosion, learning should be constructed independently, and learning methods and materials should be selectively sought through new media in order to achieve the purpose of learning.

\section{The Development of New Media Promotes the Emergence of New Educational Models}

In the survey, about $60 \%$ of the learners said that the use of new media had great help to their learning, and would like to continue using new media equipment for learning. About $35 \%$ of the learners said that the new media had a general effect on learning, while a small number of learners thought that the new media had a negative effect on their learning.

At the same time, mobile education is gradually becoming mature after market selection. According to the "New Media Alliance China Higher Education Technology Prospects 2017: Horizon Project Regional Report", it is predicted that in 2018, most of the possible technologies in China's higher education classrooms are those aimed at integrating online and offline resources, such as flipping classes and large-scale open online courses. At present, these technologies are relatively mature and closely related to the practice of education and teaching. They have been more or less tried in the field of education, and have achieved some good results. [2] As a result, mobile learning has attracted much attention abroad. In some developed countries in Europe and North America, mobile learning has been studied earlier, and the scope and content of the research are also extensive and in-depth. However, the real large-scale, national-level application of mobile learning teaching is still very few, especially in basic education, there is still a great need for development. [2]

In the next few years, both classroom teaching and online education will rely on the integration and application of big data for learning analysis and testing. Learning analysis technology and quantitative technology can test students' learning performance and activities based on specific questions and specific answers, thus providing scientific guidance for personalized education and teaching. Adaptive Learning Support System (ALSS) has brought the advantages of network into full play. It is a research hotspot to pay attention to the adaptive support of "learning" like classroom teaching. After a certain amount of accumulation and analysis of the students' learning behavior, the system will evaluate the students' performance, and determine the teaching level or the teaching materials to be used from that time point, according to the current knowledge structure and cognitive level of the learners and combined with the goal orientation. Adaptive learning will gradually become a new teaching method chosen by many schools or students, and reshaping the role of teachers will become a new challenge in the field of education and teaching.

Similarly, with the rapid development of technology, learners become more and more dependent on it, and the boundaries between formal learning and informal learning become more and more blurred. [3] In the virtual classroom based on visual technology and intelligent technology, emphasizing interaction and data analysis will help stimulate students' interest, attract students' attention and promote students' learning effect. The development of augmented reality and virtual reality technology, virtual and remote laboratory will also open the barriers between classroom education and network education. At that time, most of the practical operation learning can also be completed in any suitable place by immersion operation of virtual situation interoperable with the classroom instead of special classroom or real simulation space.

With the development of new science and technology, various new media, new means of communication, new production technology and new design concepts are constantly emerging. This also opens up a new vast space for educators and designers. Educators also face unprecedented new challenges and opportunities. Educators need to grasp the trend of contemporary culture and aesthetic orientation, and skillfully use modern educational means and technology to adapt to the information age. The Impact of New Media Technology on Education Model in the Mobile Internet Era. [4] 
Acknowledgement: This research is one of the results of the project of the Youth Fund of the Liberal Arts Office of Tongji University in 2017, "Research on the New Media Teaching Assistant Model in the Mobile Internet Era".

\section{References}

1. Wang Dongdong. Research on the Constructivist Teaching Model for the Cultivation of Film and Television Creative Ability [J]. Modern Communication (Journal of China Media University), 2017,39 (07): 148-152.

2. Gao Yuan, Huang Ronghuai. Interpretation and Enlightenment of "New Media Alliance China Higher Education Technology Prospect 2017: Horizon Project Regional Report" [J]. Audiovisual Education Research, 2017, 38 (04): 15-22.

3. Guo Shaoqing, Huang Jianjun, Yuan Qingfei. Overview of the Development of Mobile Learning Applications Abroad [J]. Foreign Audiovisual Education. 2011 (05): 105-109

4. Sun Yiwen. Research on the Application of New Media Technology in Modern Educational Practice [J]. Beauty and Times (First Half Month), 2009 (12): 133-134. 